\title{
A comparison of cycling cultures in Stockholm and Copenhagen
}

\author{
Haustein, Sonja; Koglin, Till; Nielsen, Thomas Alexander Sick; Svensson, Åse
}

Published in:

International Journal of Sustainable Transportation

Link to article, DOI:

$10.1080 / 15568318.2018 .1547463$

Publication date:

2020

Document Version

Peer reviewed version

Link back to DTU Orbit

Citation (APA):

Haustein, S., Koglin, T., Nielsen, T. A. S., \& Svensson, Å. (2020). A comparison of cycling cultures in Stockholm and Copenhagen. International Journal of Sustainable Transportation, 14(4), 280-293.

https://doi.org/10.1080/15568318.2018.1547463

\section{General rights}

Copyright and moral rights for the publications made accessible in the public portal are retained by the authors and/or other copyright owners and it is a condition of accessing publications that users recognise and abide by the legal requirements associated with these rights.

- Users may download and print one copy of any publication from the public portal for the purpose of private study or research.

- You may not further distribute the material or use it for any profit-making activity or commercial gain

- You may freely distribute the URL identifying the publication in the public portal

If you believe that this document breaches copyright please contact us providing details, and we will remove access to the work immediately and investigate your claim. 


\title{
Paper accepted for publication in International Journal of Sustainable Transportation
}

Sonja Haustein, $\underline{\text { sonh@dtu.dk }}$

Till Koglin, till.koglin@tft.lth.se

Thomas Sick Nielsen, thnie@transport.dtu.dk

Åse Svensson, ase.svensson@tft.lth.se

\section{A comparison of cycling cultures in Stockholm and Copenhagen}

\begin{abstract}
This study focuses on two central Scandinavian cities - Copenhagen and Stockholm - that are generally thought to be culturally close but have deviated with respect to cycling policies and infrastructure. Based on a survey including inhabitants of Copenhagen $(\mathrm{n}=1110)$ and Stockholm ( $\mathrm{n}=1191)$, this study investigated whether cyclists in Copenhagen and Stockholm experience the transport systems in the two cities differently, and to what extent cycling perceptions can explain differences in cycling level (minutes of cycling) among cyclists. Cycling levels are much higher in Copenhagen than Stockholm, and cyclists in Copenhagen perceive a higher prioritisation in traffic, feel safer, and perceive a higher ability to reach their destinations by bike. Using ordered logit models, we examined the effect of different factors on cycling level among cyclists in both cities. Those who live in Copenhagen have higher levels of cycling even when other independent variables are included in our model. Other significant factors were employment, which increased cycling, and car access, which decreased cycling. Being female was related to higher cycling levels in Copenhagen, but not in Stockholm. The only significant cycling perception was the perceived ease and feasibility of getting to important destinations by bicycle (cycling autonomy). Results of a similar analysis including non-cyclists led to comparable results. The results suggest that differences in cycling levels between the two cities are related to the overall mobility culture of the two cities (in particular different policies, norms and infrastructure), while individual/micro-level factors, appear rather inadequate for understanding urban differences.
\end{abstract}




\section{Highlights}

- Cycling behaviours and perceptions were surveyed in Copenhagen and Stockholm.

- Cycling level (minutes of cycling) was much higher and cycling was perceived more positively in Copenhagen compared to Stockholm.

- Living in Copenhagen increased cycling when other relevant factors were controlled for.

- Other significant factors included being employed and not having access to a car.

- A significant interaction was found between gender and city of residence.

\section{Keywords}

Cycling; Urban; Cycling culture; Transport policy; Scandinavia 


\section{Introduction}

Today the transport systems in many cities around the world create many problems, especially through their focus on motorised traffic. These problems consist, among other things, of pollution, congestion, health issues, and social exclusion (Banister, 2005; Nuhn \& Hesse, 2006; van Wee, 2007). Cycling offers part of a solution as an active mode of transport that is inexpensive, healthy, free from local emissions, and consumes very little space compared to motorised traffic (Garrard et al., 2012; Götschi et al., 2016; Fishman, 2016). Smaller and larger cities around the world are working to realize the potential of cycling in order to decrease congestion and pollution and to increase their citizens' health (Buehler \& Pucher, 2012a, b; Fishman, 2016; Garrad et al., 2012; Handy, van Wee, \& Kroesen, 2014; Lanzendorf \& Busch-Geertsema, 2014; Pojani, Bakija, Shkreli, Corcoran, \& Mateo-Babiano, 2017; Pucher \& Buehler, 2008).

In Denmark and Sweden, cycling is already a substantial part of everyday mobility in several cities. The capital of Denmark, Copenhagen, is often regarded as one of the best cycling cities in the world. The capital of Sweden, Stockholm, has in recent years also made efforts to increase the share of cycling in its modal split (Bastian \& Börjesson, 2017; Koglin, 2013). In this study, we compared both cities with regard to cycling levels (operationalised as average minutes of cycling at different weekdays in summer and winter), perceptions and experiences of cyclists. We understand these aspects as important parts of the different mobility cultures in both cities.

The concept of mobility culture that we refer to consists of both material and symbolic - or 'hard' and 'soft' - factors of mobility, such as the built environment on the one hand and norms and attitudes towards transport modes and neighbourhood characteristics on the other hand (see Götz, Deffner, \& Klinger, 2016; Klinger \& Lanzendotf, 2016). Both factors contribute to the development of a mobility culture since both affect people's consciousness about mobility and movements and their everyday mobility patterns (see Latham \& Wood, 2015; Koglin, 2017). We understand mobility culture as a product of the official planning and policy work in a city and of the built environment, which include inter alia the mobility infrastructure, urban density, connectivity of the infrastructure and the way people perceive and experience mobility and the use of different transport modes.

Promoting cycling through targeted policies requires an understanding of the single determinants of cycling and a recognition of the local and structural conditions of a specific 
city, including the associated infrastructure, planning policies, politics, and mobility patterns and how they work together in forming a specific mobility culture.

This paper starts from the assumption that there are differences in the mobility cultures between Copenhagen and Stockholm, and we conducted a survey in both cities to compare the residents' cycling behaviour, perceptions, and experiences. We expected that differences in cycling levels in both cities would be related to differences in the citizens' cycling perceptions and experiences, which would reflect different transport policies and planning approaches. The experience of cycling is, according to Koglin and Rye (2014), an important aspect to consider in order to develop a bicycle-friendly urban transport system. To test and track the roots of the differences in cycling levels between the two cities, we analysed the effects of perceptions and experiences in relation to infrastructure provision, urban density, and sociodemographics in ordinal regression models. We expected that the city as a factor explaining differences in cycling levels, would lose significance, when taking different cycling perceptions and experiences into account, in addition to other relevant background variables.

\section{Determinants of cycling}

In this section, we provide an overview about relevant determinants of cycling identified in previous studies and describe to what extent they are considered in the present study.

\subsection{Transport planning and policies}

Transport planning and policies are relevant steering tools for increasing cycling (e.g. Pucher \& Buehler, 2006; 2008). Important factors that influence transport planning and policies in a city include the historical context (e.g., the development of car industry), the economic history of the city (e.g., growth or decline), and planning traditions and cultures (e.g., whether the city has traditionally been planned for cars or bicycles, etc.), and these can affect both the concrete outcome of transport planning and the transport policies that are enacted (Koglin, 2013). Furthermore, Koglin (2015a) has shown that the organisation of a city's planning department plays an important role in how cycling is perceived in planning and how this affects the outcome of planning for cycling.

With the "politics of mobility”, Cresswell (2010) developed a theory that was further developed by Koglin and Rye (2014) into a theory of the "politics of vélomobility”. Both theories have a bearing on bicycle planning. Koglin and Rye (2014, p. 220) suggest four 
major aspects that draw on Cresswell's theory and should be targets for bicycle planning when aiming to increase the level of cycling. Firstly, the physical movement from A to B should be supported by providing infrastructure without obstacles that enables a free cycling flow. Secondly, power relations between different groups that share the space in traffic have to be considered. Thirdly, a positive representation of cycling is important, and finally the everyday practice and experience of cycling has to be considered, meaning that the everyday life of people should be facilitated through cycling and not hampered.

The focus of this article is on the fourth aspect of the politics of vélomobility because we deal with the cyclists' experiences of cycling in Copenhagen and Stockholm.

\subsection{The built environment}

In addition to, and as a result of transport policy and planning, the built environment has been shown to influence cycling. Associated factors include urban density and accessibility, which are likely to be important preconditions for shorter travel distances that favour cycling (Nielsen et al. 2013a). Additionally, 'micro environment' features have been focused on to extend the concept of walkability to bikeability. Areas might be more or less 'bikeable' based on access conditions, environmental qualities, and provisions for cars and pedestrians/bicycles (Frank et al., 2010; Madsen et al., 2013). It has been shown that both, the actual and the perceived bikeability are related to cycling (Ma \& Dill, 2017).

The specific role of infrastructure provision for bicycles has also received a high level of attention, and studies generally indicate that both the supply of bicycle infrastructure and its format (e.g. protected bike lanes) has significant effects on cycling across mobility cultures (Buehler \& Dill, 2016; Buehler \& Pucher, 2012; Chataway et al., 2014; Dill \& Carr, 2003; Pucher \& Buehler, 2017; van Goeverden et al., 2015). However, few studies have contrasted the role of local and micro-environmental factors or service levels with city-wide provisions. According to Klinger and Lanzendorf (2015), cycling - as compared to other modes - seems more affected by city-wide or "cultural” attributes, such as the perceived acceptance of cyclists than by specific local/neighbourhood characteristics.

\subsection{Individual, social, and cultural factors}

There are several individual and cultural factors that have an impact on cycling. Socioeconomic factors such as age, gender, and income have been identified as relevant determinants of cycling, but their effect varies considerably between regions. In countries 
with low cycling frequencies, such as Australia, the US, and the UK, men are found to cycle more (Aldred, Woodcock, \& Goodman, 2016; Heesch, Sahlqvist, \& Garrard, 2012; Heinen et al., 2011, Heinen et al., 2010), while this is not the case in high-cycling countries, such as Denmark, Germany and the Netherlands (e.g., Aldred et al., 2016; Garrard, 2003). In some studies, cycling is found to decline with increasing age, but not in other studies, and also here, the overall level of cycling seems to be relevant showing a higher inclusion of older people in high-cycling countries (Aldred et al., 2016). The effect of income on cycling is more ambiguous (see Heinen et al., 2010).

Apart from regional effects, the level of cycling might also depend on which other factors are controlled for in the analysis (e.g. health in case of age or car ownership in the case of income). In addition to household structure (Sottile et al., 2018) and employment status (Heinen et al., 2010), perceived constraints related to family and household demands (e.g. delivery of children) have been found to hamper cycling (e.g., Bonham \& Wilson, 2012; Pooley et al., 2013) and so have related perceived mobility needs (Hunecke et al., 2007). However, travel mode decisions are not only influenced by functional aspects, such as saving travel time and money, but also by symbolic and affective motives such as status, autonomy, and excitement related to travel modes (e.g., Anable \& Gatersleben, 2005; Ellaway et al., 2003; Hunecke et al., 2007; Pojani et al., 2017; Steg, 2005). With regard to cycling, in particular perceived autonomy and excitement have been identified as important factors (Hunecke et al., 2010), while perceived danger has been found to decrease cycling (e.g., Haustein, 2012; Pooley et al., 2013). Aldred and Goodman (2018) additionally found that newer cyclists in the UK experience near misses often as deliberate and thus as very frightful, while people who live in high-cycling areas, perceive incidents as less deliberate. Thereby new cyclists might be discouraged and existing cyclists encouraged to cycle, so that existing differences persist.

In addition, social norms have been identified as determinants of cycling (e.g., de Bruijn et al., 2005). Recent qualitative studies indicate that the use of cycling as a transport mode depends on how cycling is perceived in society as a whole, that is, whether it is seen as 'odd' or 'normal' behaviour (Pooley et al., 2013) or as ‘cool' or 'uncool' (Underwood et al., 2014); whether the bicycle is regarded as a 'cheap vehicle for the poor' or an element of a fashionable environmentally-conscious lifestyle (Pojani et al., 2017). In low-cycling countries, infrastructure has been shown to help normalise cycling where it so far has been viewed as an activity only for a few people (Aldred et al., 2017; Aldred \& Dales, 2017). 
Cultural norms within the family also seem to play a role for taking up cycling as indicated by studies from the Netherlands where adolescents from non-Western backgrounds were found to be less likely to cycle than native Dutch adolescents (Bere et al., 2008; de Bruijn et al., 2005). In the Netherlands and Denmark, a non-Western background has been found to significantly decrease the likelihood of cycling, also when controlling for relevant background variables (Haustein, Kroesen, \& Mulalic, 2018). In low-cycling countries, like the US, the opposite is the case as immigrants cycle more than natives and drive less, also when relevant background factors are controlled for, indicating an influence of the cultural background (e.g. Chatman, 2014; Smart 2010; Tal \& Handy, 2010).

Together with the actual cycling pattern in a region, the different material and sociallyconstructed aspects discussed above form specific socio-cultural settings that are referred to as mobility culture (see Götz et al., 2016; Haustein \& Nielsen, 2016; Klinger et al., 2013) - or more specifically in the case of cycling as cycling culture (Carstensen \& Ebert, 2012; Pelzer, 2010).

Different studies have compared cities or regions with the aim of describing or explaining the specific cycling culture in one region in contrast to another, partly with the aim of identifying ways to increase cycling levels in the regions with the lower cycling levels (e.g. Aldred \& Jungnickel, 2014; Carstensen \& Ebert, 2012; Pelzer, 2010). According to a study by Haustein and Nielsen (2016) that differentiates between different European mobility cultures, the two countries that are considered in this paper belong to different European mobility cultures. Denmark belongs to a group of countries where "green” cyclists are overrepresented as well as people who cycle for practical reasons. Sweden belongs to a group of countries where green travellers of all travel modes are overrepresented, and thus a high ecological awareness with regard to traffic in general can be observed.

\section{Comparing Copenhagen and Stockholm}

In the present study, we compared Copenhagen and Stockholm because these two Scandinavian capital cities have different cycling cultures as indicated by substantial differences in the mode share of cycling in the cities (see Table 1). Overall, the two cities are similar with well-organised and strong planning departments, quite good public transport systems, overall good public infrastructure and a high level of wealth. 
In this study, Stockholm and Copenhagen are defined as the city within the municipal and thus administrative border. Commuter traffic from the surrounding municipalities is not considered. Stockholm is larger than Copenhagen, while Copenhagen has a higher population density and is more flat (see Table 1 for more details). Figure 1 provides a map of both cities and their position in their functional urban areas.

The weather condition in both cities are very similar with cold winters and mild summers notwithstanding that winters are slightly colder in Stockholm (-1.8 C on average) than in Copenhagen (-1.4 C on average) (City of Stockholm, 2017; City of Copenhagen, 2017; DMI The Danish Meteorological Institute, 2017; Koglin, 2013; SMHI - The Swedish

Meteorological and Hydrological Institute, 2017).

Moreover, Copenhagen portrays itself as a cycling city (City of Copenhagen, 2011), which is also reflected in several journal articles (Buehler \& Pucher, 2012b; Pucher \& Buehler, 2008; Koglin 2015a), whereas Stockholm is not seen as a cycling city (e.g. Koglin, 2013). Thus, a comparison of the two similar cities is reasonable and might offer new insights for developing bicycle policies.

In both cities, the infrastructure and urban forms were adapted for motorization in the decades immediately following the Second World War, but this was followed by a deviation in pathways in the two cities starting in the 1970s. In this period, Stockholm developed a metro system while significantly modifying street layouts in its central areas to accommodate increasing motorization. Copenhagen - after having dismantled its tram-way system and some bicycle infrastructure in the 1950s and 60s - abandoned plans for large scale changes to improve access for cars and initiated an extension of its cycling infrastructure in the 1970s and early 80s. (Carstensen et al., 2015; Koglin, 2013). This included the addition of designated cycling lanes to key connectors from surrounding urban neighbourhoods into the city centre. 
Table 1: Characteristics of Stockholm and Copenhagen

\begin{tabular}{|c|c|c|}
\hline & Stockholm & Copenhagen \\
\hline \multicolumn{3}{|l|}{ General city characteristics } \\
\hline Inhabitants & 924000 & $696000^{a}$ \\
\hline City area $\left(\mathrm{km}^{2}\right)$ & $188 \mathrm{~km}^{2}$ & $97 \mathrm{~km}^{2}$ \\
\hline Population density (inhabitants/ km²) & 4915 & 7175 \\
\hline Topography (highest point / average slope) & $92 \mathrm{~m} / 5.7 \%$ & $37 \mathrm{~m} / 1.9 \%$ \\
\hline \multicolumn{3}{|l|}{ Transport infrastructure } \\
\hline Number of bus lines ${ }^{b}$ & 63 & 66 \\
\hline Number of light rail/metro lines ${ }^{\text {b }}$ & 7 & 2 \\
\hline $\begin{array}{l}\text { Kilometres of cycleways or infrastructure with facilities } \\
\text { for cycling (OSM, 2015) }\end{array}$ & 820 & 390 \\
\hline Density of cycling infrastructure & 4.4 & 4.0 \\
\hline Number of cars per 1000 inhabitants & 375 & 258 \\
\hline Car parking policy / price & $\begin{array}{c}\text { 0.5-4.7 EUR } \\
\text { /hour regular } \\
\text { parking and } \\
\text { 340-1247 EUR } \\
\text { / year for } \\
\text { residential } \\
\text { parking }\end{array}$ & $\begin{array}{c}\text { 1.2-4.8 EUR } \\
\text { /hour regular } \\
\text { parking and } \\
\text { 13-147 EUR / } \\
\text { year for } \\
\text { residential } \\
\text { parking }\end{array}$ \\
\hline Car registration tax & only VAT & $\begin{array}{l}105 \% \text { of value } \\
\text { up till } 14300 \\
\text { EUR, } 150 \% \text { of } \\
\text { value }>14300\end{array}$ \\
\hline Mean commute trip length for residents (all modes) & $11 \mathrm{~km}$ & $10 \mathrm{~km}$ \\
\hline Bicycle share in $2005 / 2006$ & $4 \%$ & $25 \%$ \\
\hline Bicycle share in $2011 / 2013$ & $3 \%$ & $27 \%$ \\
\hline
\end{tabular}

Notes: Topography derived from EU-DEM model (European Commission, 2017), cycling infrastructure is from OpenStreetMap (2015) data. The Danish registration tax is reported based on conditions prior to 2017. Value deductions additionally lowers the tax rates based on environmental and safety performance of vehicles. The data for the bicycle share came from the databases for the national travel surveys in Sweden 2005/2006 and 2012/2013 and Denmark (TU) 2006/2007 and 2012/2013. We calculated the bicycle share for all trips that start or end in the city of Stockholm or Copenhagen.

ancluding 105.000 residents of Frederiksberg municipality, which is located inside the borders of Copenhagen.

${ }^{\mathrm{b}}$ Public transport measures in the table refer to the area within the two cities. Total public transport provision in bus or train km amounts to $69 \mathrm{~km} / \mathrm{capita} /$ year in Stockholm's Functional Urban Area and 70-72 km/capita/year in Copenhagen's Functional Urban Area. The delineation of the Functional Urban Area compared to the city can be seen in Figure 1. 
The position of cycling in Copenhagen's transport planning was further formalized with the introduction of a 'Bicycle Account' in 1995 as an account of conditions for cyclists in Copenhagen based on infrastructure and transport statistics as well as measures of satisfaction and perceived safety/comfort. Notably the 'Bicycle Account' was also introduced as a tool to promote cycling over driving (City of Copenhagen, 1996). The efforts to evaluate cycling conditions were later extended to include quantitative objectives for the promotion of cycling including the mode-share objective that $50 \%$ of all trips to places of work or education should be on bicycle by 2015 (Nielsen et al., 2013b; v. Goeverden et al., 2015). Cycling objectives for Stockholm came considerably later and were more modest, for example that $15 \%$ of peakhour trips should be on a bicycle by 2030 (City of Stockholm, 2012).

Moreover, since the Second World War, the policy in Copenhagen has been to expand the bicycle infrastructure, also due to limitations in funding for larger transport projects. This highly affected transport planning in Copenhagen. By contrast, Stockholm had more funding opportunities after the Second World War and heavily invested in a subway system and innercity highway and did not consider cycling in the infrastructure investments. Also today, Copenhagen designates more funding to bicycle infrastructure than Stockholm and has a whole division for bicycle planning, which Stockholm does not have (Koglin, 2013; 2015a). These aspects most probably contribute to the differences between Stockholm and Copenhagen in terms of cycling.

In this paper, differences between the cities are taken into account by subjective perceptions regarding cycling as well as objective factors measurable at a district level (population density, elevation difference, cycleway density). As most other objective factors are the same for all people living in either Copenhagen or Stockholm, they can only be captured in an overall city factor (city dummy).

\section{Method}

\subsection{Procedure and participants}

This paper is based on two identical mail back surveys: one conducted in Copenhagen (provided in Danish language) and one in Stockholm (in Swedish). Data were collected during the spring of 2011 in both cities where 3,012 questionnaires where sent out in Stockholm and 3,005 in Copenhagen to citizens aged 18 and older. 
The selection of the participants was stratified, which means that the same number of questionnaires was sent to every district in Stockholm and Copenhagen (see Figure 1). The sample was randomly drawn from the respective national register of persons. The paper and pencil questionnaire was accompanied by an information letter and a prepaid envelope to return the questionnaire. Reminders to fill in the questionnaire were sent out two times to raise the response rate. The first reminder was sent out after two weeks, the second reminder two weeks later. The second reminder included the complete material again (questionnaire, letter, envelope). Reminders were only sent to people who had not returned the questionnaire yet (tracked by an id). Participation in the survey was voluntary and no incentives were provided.

In Stockholm, the response rate was 39.5\% (1,191 responses), and in Copenhagen it was $36.6 \%$ (1,100 responses). Response rates varied between $22 \%$ and $66 \%$ in the different districts, with lower response rates in districts farther away from the central areas of both cities. Differences in response rates between districts may reflect differences in the level of education as well as differences in the perceived relevance of the survey topic for the target population, which is likely to be higher in the more dense and congested parts of the city. Data were entered by an IT consultant company in Sweden (see http://www.infodatait.se/) according to coding scheme provided by one of the authors. 


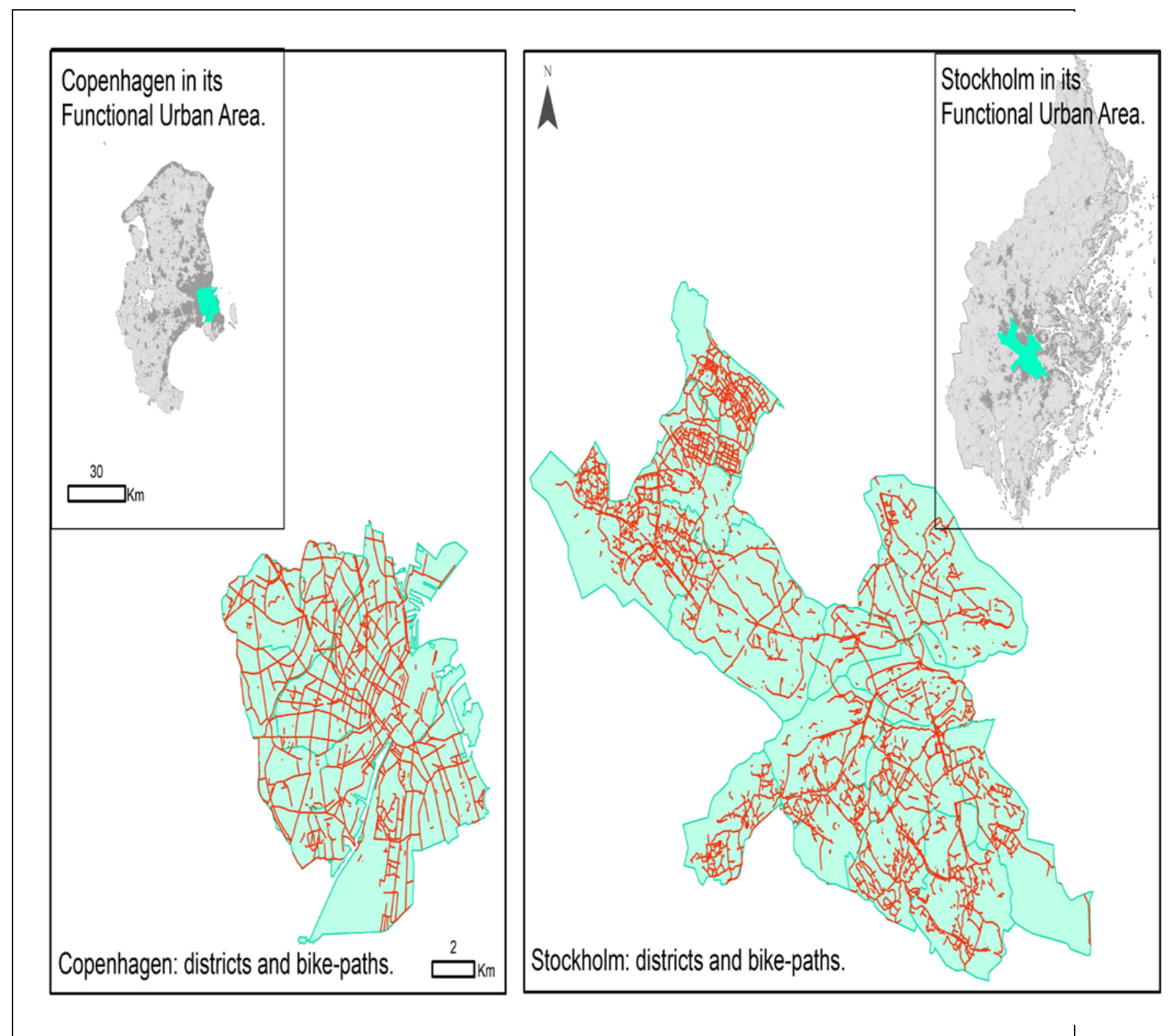

Figure 1: The location of Copenhagen and Stockholm in their Functional Urban Areas - as well as the delineation of the 12 districts of Copenhagen (left) and the 14 districts of Stockholm (right) and their respective networks of bicycle infrastructure. Cycling infrastructure are mapped based on cycling-tags in Open Street Map (2015). Urban land cover of the surrounding areas is indicated in dark grey based on Corine landcover data (EEA, 2015). The maps are drawn at comparable scales. 


\subsection{Measures}

The questionnaire included questions about the time spent using all common modes of transport (car, walking, cycling, and public transport) on regular weekdays, Saturdays, and Sundays in the summer (April-September) and winter period (October-March). For each day category within a season, the respondents could choose among seven time intervals ( 0 min, 1$20 \mathrm{~min}, 21-40 \mathrm{~min}, 41-60 \mathrm{~min}, 61-80 \mathrm{~min}, 81-100 \mathrm{~min}$, and >100 min) for each transport mode $^{1}$.

Respondents were additionally asked about their experience of traffic and mobility in Copenhagen or Stockholm when using different transport modes.

With regard to cycling, respondents who cycled at least one minute, were asked questions about their perceived level of stress and safety when cycling in their city, whether they perceived that cycling was prioritised compared to other modes of transport, and if they could reach their important destinations by bike (see Figure 3 for the wording of the items). The item formulation was inspired by the aspects that were identified as relevant in relation to Cresswells' politics of mobility (2010). Respondents were asked to assess their level of agreement using a 5-point Likert scale (1 = “totally disagree” to 5 = “totally agree”). Finally, all respondents (i.e. also non-cyclists) had to rank the four main modes of transport (public transport, car, bicycle, walking) to reflect the transport modes' current prioritisation in their city both as they perceived it to be (actual prioritisation) and how they would like it to be (desired prioritisation).

Background variables included age, gender, income, level of education, having a driver's license, having access to a car ( 1 = “never” to 4 = “always”), household structure, and employment status.

Urban variables were added to the survey data based on district of residence. These variables included population density in the urban area of each district based on population statistics and Urban Atlas land use data (European Union, 2011; Københavns Kommune, 2015,

\footnotetext{
${ }^{1}$ Translation of the question: "How much time do you spend with different transport modes in traffic in Copenhagen/Stockholm? Mark with a cross the time interval that best matches with the time you usually spend in traffic in summer and winter, on regular weekdays, Saturdays and Sundays.”
} 
Stockholms Stad, 2014), elevation differences drawn from Copernicus EU-DEM data layers, and the density of bicycle infrastructure (cycleways, tracks, and lanes) as defined based on Open Street Map data (OpenStreetMap, 2015). The resulting variable 'cycleway density’ provides a measure of the access to and coverage of bicycle facilities in the districts. 


\subsection{Analysis}

Descriptive statistics (frequencies and means) were used to provide an overview of cycling level and cycling perception. Differences in cycling levels and perceptions between the cities were tested by Mann-Whitney U-tests and t-tests depending on the scale of the measurement. Differences within the same city, cycling frequencies in different seasons, and differences between actual and desired cycling prioritisation were compared with Wilcoxon tests for related samples.

A principal component analysis with Varimax rotation was used to identify the underlying dimensions of different cycling perceptions. The analysis was done for both cities combined.

Ordered logit models were used to test the effect of spatial variables (including living in Stockholm vs. living in Copenhagen), socio-demographic variables, and cycling perceptions on cycling level. We conducted two sets of models: the first based only on cyclists, the second based on all participants. As cycling perceptions (apart from cyclist prioritisation) were only assessed by cyclists, they could only be included in the analysis including cyclists.

\section{Results}

\subsection{Respondents’ general background}

The respondents' average age was 46 years in Copenhagen and 51 years in Stockholm, thus participants in Stockholm were on average older than participants in Copenhagen (t-test, $\mathrm{p}<$ .001). The gender distribution was almost even in both cities; in Stockholm $51 \%$ of the respondents were men and in Copenhagen it was 53\%. In Stockholm, 57\% had a higher education, while this number was 58\% in Copenhagen. Differences between respondents from Copenhagen and Stockholm with regard to gender and education were not significant (Chi ${ }^{2}$ test, $\mathrm{p}>.10)$.

The respondents were compared to the total adult population in each city with regard to age and gender. Average age in Copenhagen was 42 years and it was 46 years in Stockholm; the share of men was 49\% in both cities (Statistiska Centralbyrån, 2018; Danmarks Statistiks, 2018). Thus, older people and men are slightly overrepresented in our survey.

When only considering cyclists (defined as persons who cycled for at least one minute in one of the different time categories), the average age in Copenhagen was 41 years and the gender 
distribution was $46 \%$ men. In Stockholm, the average age of cyclists was 47 years and the gender distribution was $50 \%$ men. In both cities, $63 \%$ of the cyclists had a higher education.

For the case of Copenhagen, we could compare cyclists in our sample to cyclists in Copenhagen based on the sample from the Danish national travel survey (TU). Following the TU sample, the average age of a cyclist living in Copenhagen is 37 years, $45 \%$ are men, and $60 \%$ have a higher education (university/diploma/bachelor level). Thus, again our sample has a slight overrepresentation of older residents (who are generally more willing to answer surveys) but is generally very close to the population that it represents.

Car access was slightly higher in Stockholm than in Copenhagen ( $<$.01): in Stockholm 17\% of participants reported to never have access to a car, 13\% rarely, $14 \%$ sometimes, and 53\% always, while the corresponding percentages in Copenhagen were 15\% (never), 22\%, 15\%, and $48 \%$ (always).

From the data described above, one can conclude that the respondents in both cities have similar socio-economic backgrounds, apart from people in Copenhagen being a bit younger and having a bit lower car access.

\subsection{Cycling in Stockholm and Copenhagen}

As Figures 2 shows, respondents in Copenhagen used bicycles more per day than respondents in Stockholm both in summer and in winter and for all weekdays. Differences in all six categories were significant in $U$-tests $(p<.001)$. Further, it seems that the use of the bicycle as a mode of transport was more affected by the season in Stockholm than in Copenhagen. However, the differences in cycling duration between summer and winter were significant both in Copenhagen and Stockholm as tested by Wilcoxon tests for related samples $(p<$ $.001)$. 


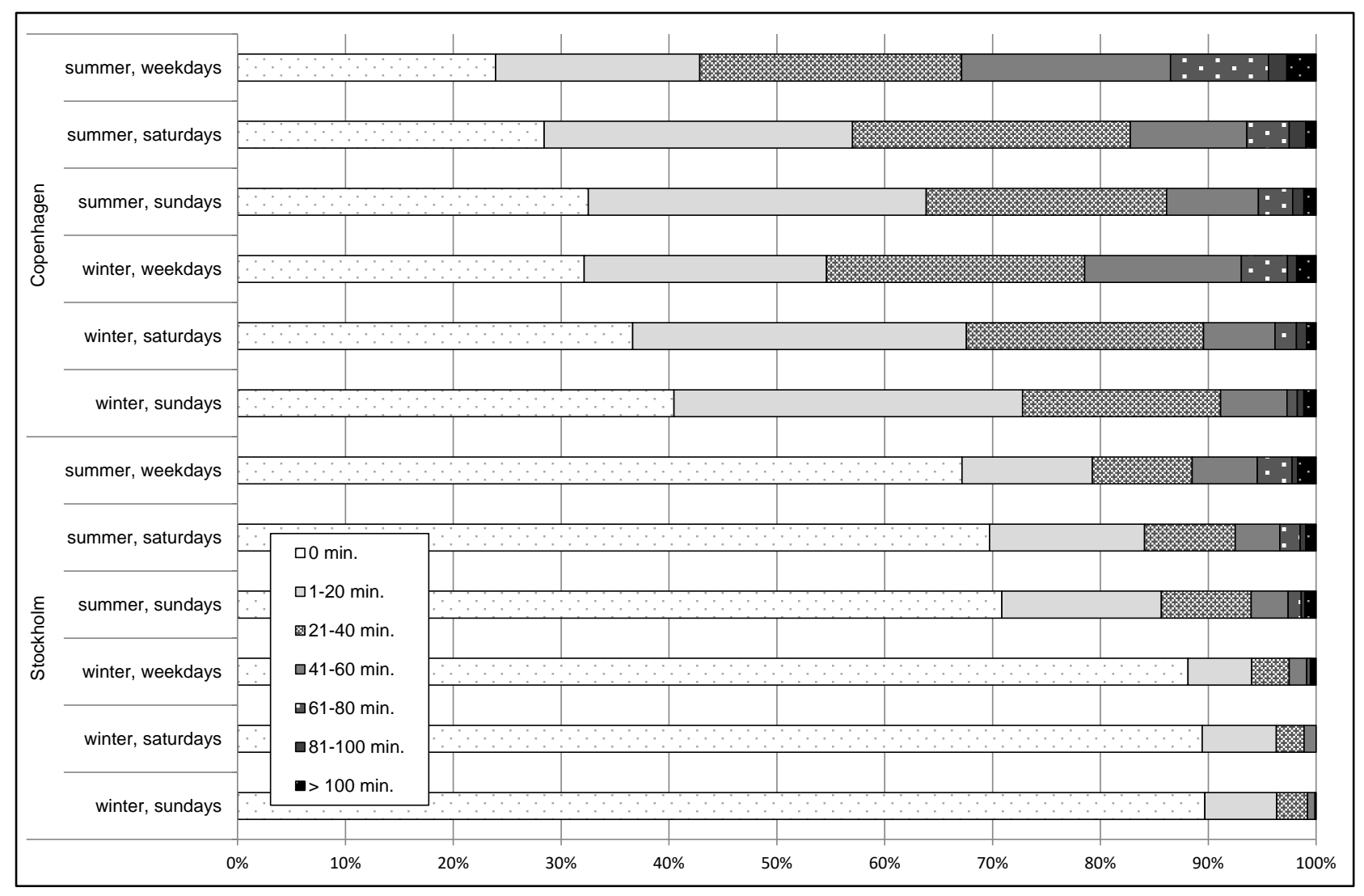

Figure 2: Minutes cycled per day in summer and winter in Copenhagen and Stockholm

\subsection{Differences in cycling perceptions in Stockholm and Copenhagen}

Figure 3 shows how citizens of Copenhagen and Stockholm experienced cycling in their respective cities and how they perceived the cities' cycling policies and planning. The figure shows the mean scores calculated from respondents who had at least some experience of cycling in the city (i.e. they cycled at least one minute per week). Cycling perceptions were significantly more positive in Copenhagen than in Stockholm (all $\mathrm{p}<.001$ in t-tests), except for perceived cycling stress where no significant difference was found ( $p>.10)$. We believe this can be explained by the higher level of cycling congestion in Copenhagen and a poorer infrastructure for cycling in Stockholm (see Koglin, 2013). The largest discrepancy between the cities was found in relation to cycling policies and planning. The differences in perceived safety and security as well as in the perceived efficiency of cycling were also high.

Given the large differences in cycling levels between the two cities, the differences in cycling perceptions might have been expected to be larger. As only cyclists were asked for their perceptions, people who do not cycle because of high dissatisfaction were not considered, which probably reduced the differences between participants of both cities. 


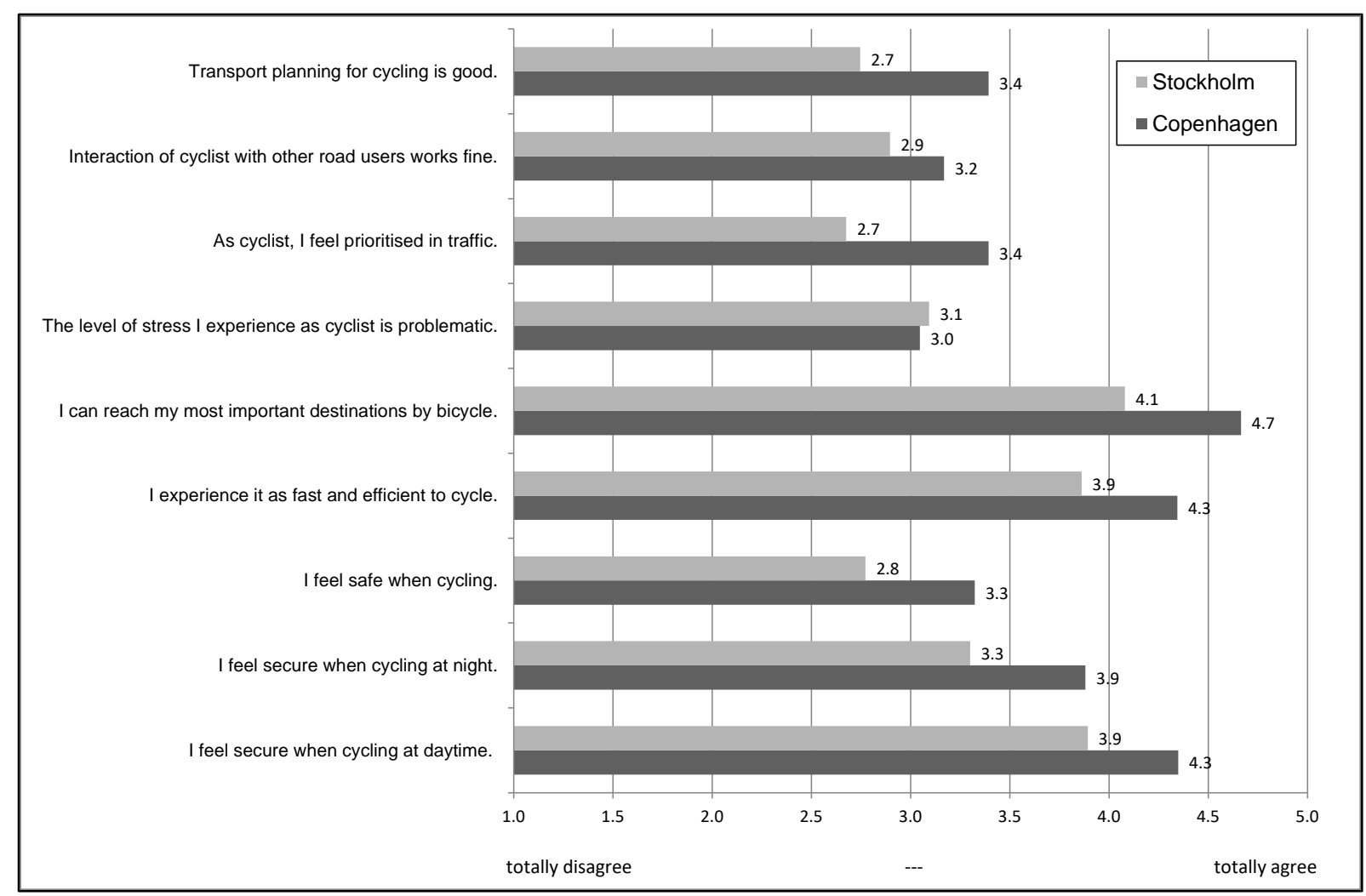

Figure 3: Mean scores for cycling perceptions among respondents in Copenhagen and Stockholm

A principal component analysis (PCA) was conducted to determine if the individual cycling perceptions could be assigned to distinct factors. The PCA resulted in a 3-factor solution that explained 65\% of the variance, and these factors were interpreted as "Cycling priority in planning”, “Cycling safety and security”, and “Cycling autonomy”, that is the perceived ease and feasibility of getting to important destinations by bicycle. The loadings of the items on each of the three factors are shown in Table 2 . With a factor loading above .6 on one of the three factors, all items except for two could clearly be assigned to one of the three factors. The level of stress experienced as a cyclist had a high loading (-.53) on the first factor (Cycling priority in planning), but as regards content we did not consider cycling stress as belonging to this factor. The negative loading can be interpreted that being prioritised as a cyclist reduces cycling stress - but cycling stress is not regarded as part of the same dimension. Thus, this item was excluded from further analysis. The second item not clearly belonging to one of the factors was feeling safe when cycling, which had a relatively high loading both on factor 1 (.52) and factor 2 (.57). Based on its content and the higher loading, we allocated the safety item to factor 2 (Cycling safety and security). 
Table 2: Results of a principle component analysis of the cycling perception items

\begin{tabular}{|c|c|c|c|}
\hline & 1 & 2 & 3 \\
\hline & $\begin{array}{c}\text { Cycling } \\
\text { priority in } \\
\text { planning }\end{array}$ & $\begin{array}{c}\text { Cycling } \\
\text { safety and } \\
\text { security }\end{array}$ & $\begin{array}{l}\text { Cycling } \\
\text { autonomy }\end{array}$ \\
\hline As cyclist, I feel prioritised in traffic. & .768 & -.027 & .302 \\
\hline Transport planning for cycling is good. & .735 & .033 & .282 \\
\hline Interaction of cyclist with other road users works fine. & .715 & .314 & .001 \\
\hline I feel secure when cycling at daytime. & .112 & .804 & .268 \\
\hline I feel secure when cycling at night. & .071 & .802 & .293 \\
\hline I feel safe when cycling. & .523 & .569 & -.014 \\
\hline I experience it as fast and efficient to cycle. & .307 & .317 & .657 \\
\hline I can reach my most important destinations by bicycle. & .054 & .187 & .845 \\
\hline The level of stress I experience as cyclist is problematic. & -.528 & -.381 & .276 \\
\hline Cronbach’s alpha & .72 & .73 & .68 \\
\hline
\end{tabular}

In line with the described allocation to factors, we calculated three mean scales. With Cronbach's alpha values of around .7, the scales had acceptable internal consistencies (see Table 2).

Not surprisingly, when knowing the differences with regard to the single items, cyclists in Copenhagen and Stockholm differed significantly in all three cycling perception scales: cyclists in Copenhagen perceived a higher prioritisation in traffic $\left(\mathrm{M}_{\mathrm{C}}=3.3\right.$; $\mathrm{M}_{\mathrm{s}}=2.8, \mathrm{p}<$ $.001)$, they felt more safe and secure as cyclists $\left(\mathrm{M}_{\mathrm{C}}=3.8 ; \mathrm{M}_{\mathrm{S}}=3.3, \mathrm{p}<.001\right)$, and they perceived a higher cycling autonomy $\left(\mathrm{M}_{\mathrm{C}}=4.5 ; \mathrm{M}_{\mathrm{S}}=3.9, \mathrm{p}<.001\right)$. With regard to gender, men perceived a higher level of safety and security $(M=3.2)$ compared to women $(M=3.0$, $p$ $<.001)$, and they also perceived a higher level of cycling prioritisation in their city $(\mathrm{M}=3.7$ vs. $3.5, \mathrm{p}<.01)$. In contrast, there was no significant difference with regard to perceived cycling autonomy $(\mathrm{M}=4.3$ for both genders, $\mathrm{p}>.10)$. Correlations of the three scales with age were all below .2 and thus not considered further. 


\subsection{Prioritisation of transport modes in Copenhagen and Stockholm}

All respondents (also non-cyclists), were asked to rank the four transport modes (public transport, car, cycling, walking) with regard to the actual prioritisation in their city and the desired prioritisation. The means for each transport mode separated by city are shown in Figure 4.

The rank differences between the cities were significant for each of the transport modes in Mann-Whitney U-tests ( $\mathrm{p}<.05$ ), except for the desired prioritisation of walking ( $>.10)$. In Copenhagen, cycling was on average perceived as the most prioritised in traffic, while in Stockholm cycling was on average ranked as the third most prioritised in traffic. In Stockholm, public transport was regarded as most prioritised followed by the car, while in Copenhagen public transport and the car were regarded as less prioritised than cycling. Walking was regarded as the least prioritised in both cities. With regard to the desired prioritisation, we found that citizens of Copenhagen wanted both cycling and public transport to be more prioritised than they perceive it today, while they wanted the car to be prioritised less. In Stockholm, public transport was by far the transport mode citizens wanted to see as most prioritised, and the differences between the other modes were not so pronounced as in Copenhagen.

When comparing the actual with the desired rank separately for each mode and city, we found significant discrepancies for each mode and city ( $\mathrm{p}<.001$, Wilcoxon test), except for walking in Copenhagen $(\mathrm{p}>.10)$ and cycling in Stockholm $(\mathrm{p}=.08)$ where the actual and desired rank did not differ significantly. The most pronounced difference between actual and desired prioritisation referred to the car in Copenhagen. There was consistency between Copenhagen and Stockholm regarding walking, and the desired prioritisation equalled the actual prioritisation, which was low in both cities. In both cities, the desired prioritisation for public transport was considerably higher than the actual prioritisation, while it was the other way around for car traffic. In both cities, the desired prioritisation for cycle traffic was somewhat higher than the perceived actual priority. Similar results have been found by Koglin (2018). 


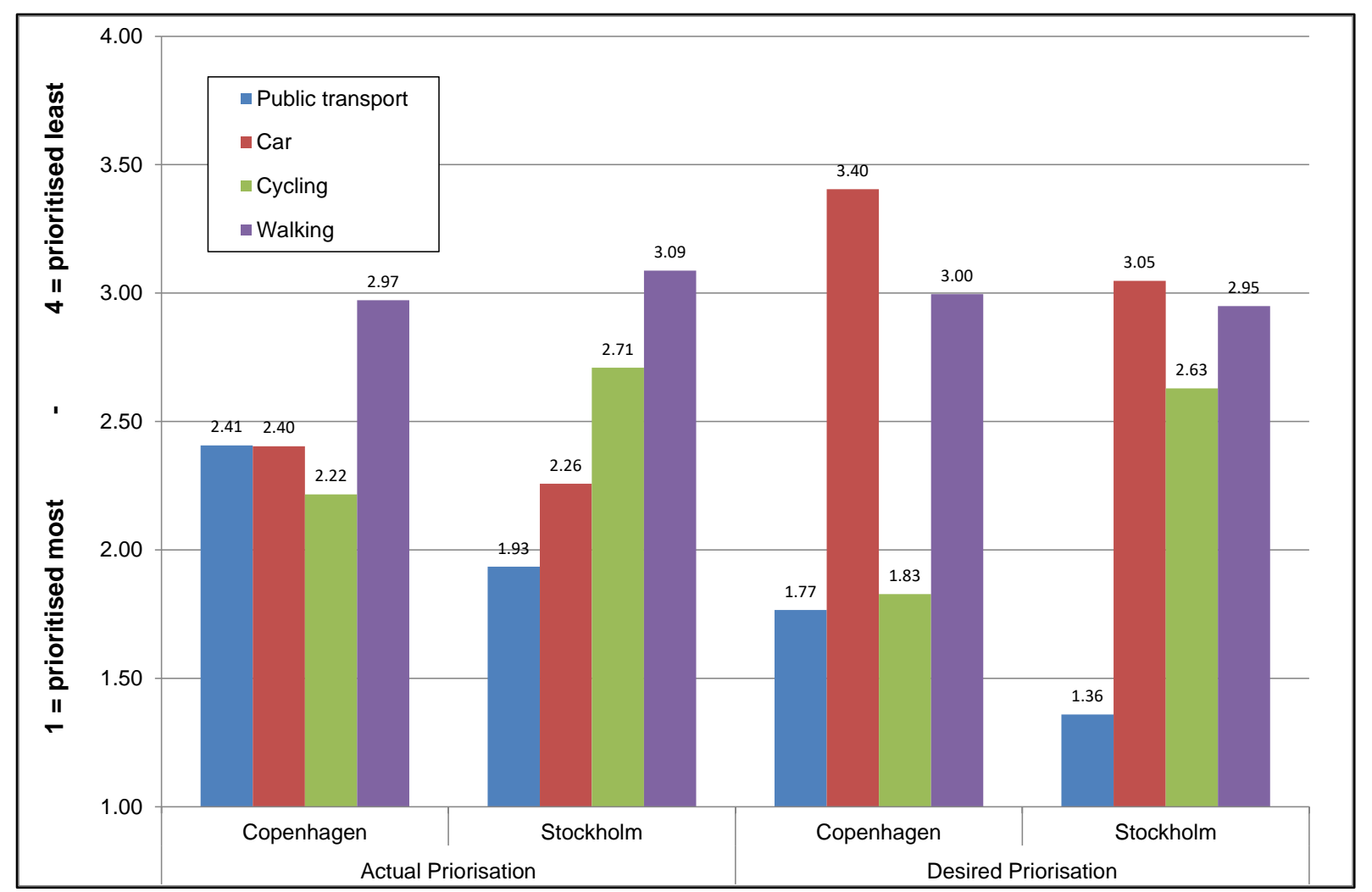

Figure 4: Perceived actual prioritisation of transport modes and desired prioritisation (1 = first rank/prioritised most, 4 = last rank/prioritised least).

\subsection{Factors related to cycling level}

At this point in the analysis, we could show that citizens of Stockholm cycle less compared to citizens of Copenhagen and that cyclists in Stockholm have less positive perceptions about cycling. However, we did not yet know to what extent the different cycling frequencies were related to these different perceptions or if they could be traced back to other factors such as spatial or socio-demographic factors.

To learn more about the relation between the different factors, we conducted ordinal regression analyses with a "cycling level index" as the dependent variable. The cycling level index was based on the mean of the six cycling level variables ("minutes per day cycling on weekdays/Saturdays/Sundays in summer (April-September)/ and winter (October-March)), each of them assessed by seven categories, see Section 4.2). Persons who did not report any cycling perceptions because they never cycle were not included in this analysis.

In the model, we first entered the city and other spatial factors on district level (population density, elevation difference, and cycleway density measured as km of cycle paths or lanes 
per square km of urban land; see Table 3, Model 1a), then we entered socio-demographic variables (Table 3, Model 2a), and finally we entered the three cycling perception scales (Model 3a). The "proportionality of odds" assumption was met in all three models as indicated by non-significant parallel lines tests (Garson, 2014).

The results showed that living in Copenhagen compared to Stockholm had a significant positive effect on cycling level, while the additional spatial factors on the district level were not significant. The effect of the city barely decreased when socio-demographic factors were included (Model 2a). Additional significant factors in Model 2a were being a student and working (employed or self-employed), which increased cycling level, and having access to a car, which decreased cycling level. Age was not a significant factor, which can probably be explained by the relation of age and working status. However, we found a significant effect of old age (65+) and living in Stockholm, indicating that older people in Stockholm are more likely to cycle than older people in Copenhagen. We additionally found that female gender was significantly related to cycling in Copenhagen, but not in Stockholm.

When cycling perceptions were included (Model 3a), the effect of the city decreased a bit more but remained the strongest factor and highly significant. The only significant cycling perception, when controlling for all kinds of background factors, was cycling autonomy. 
Table 3: Results of ordinal regression analyses for predicting cycling level in Copenhagen and Stockholm (including cyclists only)

\begin{tabular}{|c|c|c|c|c|c|c|c|c|c|}
\hline & \multicolumn{3}{|c|}{ Model 1a (n=1545) } & \multicolumn{3}{|c|}{ Model 2a (n=1513) } & \multicolumn{3}{|c|}{ Model 3a (n=1513) } \\
\hline & $\begin{array}{l}\text { Esti- } \\
\text { mate }\end{array}$ & Wald & Sig. & $\begin{array}{l}\text { Esti- } \\
\text { mate }\end{array}$ & Wald & Sig. & $\begin{array}{l}\text { Esti- } \\
\text { mate }\end{array}$ & Wald & Sig. \\
\hline \multicolumn{10}{|l|}{ Environment/infrastructure } \\
\hline Copenhagen & 1.84 & 112.24 & .000 & 1.69 & 65.06 & 0.000 & 1.52 & 51.457 & 0.000 \\
\hline $\begin{array}{l}\text { Population density } \\
\text { (district level) }\end{array}$ & 0.00 & 1.70 & .193 & 0.00 & 0.43 & 0.514 & 0.00 & 0.141 & 0.707 \\
\hline $\begin{array}{l}\text { Elevation difference } \\
\text { (district level) }\end{array}$ & 0.02 & 0.94 & .331 & 0.03 & 1.17 & 0.280 & 0.03 & 1.108 & 0.293 \\
\hline $\begin{array}{l}\text { Cycleway density } \\
\text { (district level) }\end{array}$ & 0.02 & 0.22 & .638 & 0.00 & 0.00 & 0.982 & 0.04 & 0.916 & 0.338 \\
\hline \multicolumn{10}{|l|}{ Socio-demographics } \\
\hline Gender $\times$ Stockholm & & & & -0.12 & 0.62 & 0.430 & -0.11 & 0.45 & 0.502 \\
\hline Gender $\times$ Copenhagen & & & & 0.34 & 7.55 & 0.006 & 0.34 & 7.22 & 0.007 \\
\hline Age & & & & 0.03 & 2.14 & 0.143 & 0.02 & 1.06 & 0.304 \\
\hline Age $^{2}$ & & & & 0.00 & 2.93 & 0.087 & 0.00 & 1.37 & 0.242 \\
\hline $65+\times$ Stockholm & & & & 0.98 & 10.25 & 0.001 & 0.84 & 7.32 & 0.007 \\
\hline $65+\times$ Copenhagen & & & & 0.41 & 1.68 & 0.195 & 0.35 & 1.22 & 0.270 \\
\hline Basic education & & & & -0.37 & 3.48 & 0.062 & -0.26 & 1.70 & 0.192 \\
\hline Student & & & & 0.66 & 9.01 & 0.003 & 0.66 & 8.80 & 0.003 \\
\hline Employed or self-employed & & & & 0.47 & 8.76 & 0.003 & 0.48 & 9.09 & 0.003 \\
\hline Driving licence & & & & 0.10 & 0.48 & 0.488 & 0.06 & 0.15 & 0.701 \\
\hline Car access & & & & -0.32 & 41.44 & 0.000 & -0.30 & 34.96 & 0.000 \\
\hline \multicolumn{10}{|l|}{ Cycling perceptions } \\
\hline Cycling priority & & & & & & & -0.06 & 0.98 & 0.321 \\
\hline Cycling safety and security & & & & & & & -0.01 & 0.05 & 0.829 \\
\hline Cycling autonomy & & & & & & & 0.53 & 63.29 & 0.000 \\
\hline Nagelkerke’s $R^{2}$ & & & .187 & & & .238 & & & .277 \\
\hline Parallel lines test ( $p$-value) & & & .283 & & & .766 & & & .676 \\
\hline
\end{tabular}

Link function: logit

When interpreting the results, one should be aware that people who do not cycle at all were not included in these analyses. This was done because these persons were not able to evaluate the items in relation to cycling experience and perceptions. This, however, decreases the variance in the dependent variable and thus the possibility of the factors becoming significant compared to including non-cyclists.

Therefore, we additionally calculated the three regression analyses based on the complete sample (including non- cyclists, see Table 4). While we could not include cycling perceptions in the third model, we included the prioritisation of cyclists here instead (see Section 5.4), as this was assessed by all participants. While we again find that Copenhagen is the only significant spatial variable in all three models, most socio-demographic variables become significant now; however this is mostly due to the larger sample size as most estimates do not 
change considerably. Also the fact that the parallel lines tests become significant now, can be explained with the larger sample size (Garson, 2014). When we calculated the same analysis on a random sample of 1000 participants, the parallel lines tests were not significant anymore. The main differences between Models $1 \mathrm{a}$ and $1 \mathrm{~b}$ and $2 \mathrm{a}$ and $2 \mathrm{~b}$, respectively, is the higher amount of explained variance.

In Model 3b, we find a significant effect of cycling prioritisation; however, other than one might expect, a lower perceived prioritisation of cycling was related to higher levels of cycling, when keeping all other factors constant.

Table 4: Results of ordinal regression analysis for predicting cycling level in Copenhagen and Stockholm (including also non-cyclists)

\begin{tabular}{|c|c|c|c|c|c|c|c|c|c|}
\hline & \multicolumn{3}{|c|}{$\begin{array}{l}\text { Model 1b } \\
(n=2293)\end{array}$} & \multicolumn{3}{|c|}{$\begin{array}{l}\text { Model 2b } \\
(n=2226)\end{array}$} & \multicolumn{3}{|c|}{$\begin{array}{l}\text { Model 3b } \\
(n=1815)\end{array}$} \\
\hline & $\begin{array}{l}\text { Esti- } \\
\text { mate }\end{array}$ & Wald & Sig. & $\begin{array}{l}\text { Esti- } \\
\text { mate }\end{array}$ & Wald & Sig. & $\begin{array}{l}\text { Esti- } \\
\text { mate }\end{array}$ & Wald & Sig. \\
\hline \multicolumn{10}{|l|}{ Environment/infrastructure } \\
\hline Copenhagen & 1.81 & 177.96 & .000 & 1.66 & 96.45 & 0.000 & 1.96 & 107.77 & 0.000 \\
\hline $\begin{array}{l}\text { Population density } \\
\text { (district level) }\end{array}$ & 0.00 & 0.67 & .412 & 0.00 & 0.00 & 0.991 & 0.00 & 0.03 & 0.866 \\
\hline $\begin{array}{l}\text { Elevation difference } \\
\text { (district level) }\end{array}$ & -0.01 & .238 & .625 & -0.01 & 0.16 & 0.690 & 0.00 & 0.01 & 0.935 \\
\hline $\begin{array}{l}\text { Cycleway density } \\
\text { (district level) }\end{array}$ & -0.04 & 1.71 & .191 & -0.03 & 1.28 & 0.257 & 0.00 & 0.00 & 0.953 \\
\hline \multicolumn{10}{|l|}{ Socio-demographics } \\
\hline Gender $\times$ Stockholm & & & & -0.21 & 3.02 & 0.082 & -0.21 & 2.68 & 0.102 \\
\hline Gender $\times$ Copenhagen & & & & 0.37 & 10.77 & 0.001 & 0.28 & 5.10 & 0.024 \\
\hline Age & & & & 0.07 & 11.62 & 0.001 & 0.07 & 8.13 & 0.004 \\
\hline Age $^{2}$ & & & & 0.00 & 17.46 & 0.000 & 0.00 & 11.07 & 0.001 \\
\hline $65+\times$ Stockholm & & & & 0.89 & 13.42 & 0.000 & 0.99 & 12.21 & 0.000 \\
\hline $65+\times$ Copenhagen & & & & 0.13 & 0.26 & 0.610 & 0.03 & 0.01 & 0.926 \\
\hline Basic education & & & & -0.50 & 10.88 & 0.001 & -0.49 & 6.33 & 0.012 \\
\hline Student & & & & 0.88 & 21.57 & 0.000 & 0.95 & 20.58 & 0.000 \\
\hline Employed or self-employed & & & & 0.59 & 19.34 & 0.000 & 0.73 & 22.26 & 0.000 \\
\hline Driving licence & & & & 0.27 & 5.01 & 0.025 & 0.13 & 0.95 & 0.330 \\
\hline Car access & & & & -0.17 & 17.11 & 0.000 & -0.20 & 18.14 & 0.000 \\
\hline $\begin{array}{l}\text { Cycling prioritisation } \\
\text { (1=highest; } 4=\text { lowest } \\
\text { prioritisation) }\end{array}$ & & & & & & & 0.15 & 10.98 & 0.001 \\
\hline Nagelkerke’s $R^{2}$ & & & .230 & & & .318 & & & .326 \\
\hline $\begin{array}{l}\text { Parallel lines test ( } p \text {-value) } \\
\text { Parallel lines test, sub- }\end{array}$ & & & .024 & & & .009 & & & .072 \\
\hline sample of $N=1000$ ( $p$-value) & & & .647 & & & .068 & & & .451 \\
\hline
\end{tabular}




\section{Discussion}

The aim of this study was to investigate how cycling is practised and experienced in Copenhagen and Stockholm and how cycling perceptions influence cycling levels when socio-demographic and infrastructure are additionally taken into account.

As expected, cycling levels are much higher in Copenhagen compared to Stockholm. A large difference is seen both for weekdays and weekends and in both summer and winter - but the difference is especially remarkable during winter, where only 1 out of 10 Stockholmers is cycling while 2 out of 3 Copenhageners are cycling.

Overall, it can be concluded that cyclists in Copenhagen are more positive when it comes to safety and security while cycling, bicycling infrastructure, planning for cycling, and the prioritisation of cycling in planning, and within the transport system than their counterparts in Stockholm. The only aspect where cyclists in Copenhagen had a more negative view than cyclists in Stockholm was on the experience of stress. This is probably related to the fact that the bicycle infrastructure is more congested in Copenhagen compared to Stockholm as more people in Copenhagen use the bicycle for commuting (Koglin 2013).

Copenhageners in general also perceive bicycles as having a higher priority in traffic in their city than Stockholmers do, whereas Stockholmers perceive public transport as having a higher priority in their city. Moreover, citizens of both cities think that cars should be prioritised less in traffic, but they differ when it comes to which other modes should receive higher priority. Stockholmers primarily point to public transport, whereas Copenhageners point towards public transport and bicycles.

From these results, Stockholm appears very much like a city with a public transport culture and Copenhagen as a cycling city. That cyclists in Stockholm often feel marginalised might be the result of the history of transport planning in Stockholm that has focused primarily on motorised transport (Koglin 2013; 2015b), while cycling in Copenhagen has been a priority since the 1970s and has been increasingly in focus in recent decades where innovation and infrastructure expansion dedicated to cycling seems to have accelerated (see Carstensen \& Ebert, 2012; Koglin 2013; Nielsen et al., 2013b).

The effect of different factors on the level of cycling was examined by ordinal regression analyses. Other than expected, the city factor: Copenhagen versus Stockholm, remained highly important and significant throughout the inclusion of additional spatial factors and 
infrastructure, socio-demographic variables, car-ownership, cycling experiences and perceptions. This indicates that differences between the cities in cycling levels can only be attributed to a limited degree to these other factors. The strength of the city factor might be interpreted either as the result of omitted variables or as an effect of the combined set of attributes of each city. These may include a number of factors that are to a large degree common to the residents of each city and hard or impossible to measure at an individual level, such as weather differences, quality of bicycle or public transport networks, or interactions with the surrounding region that affect trip distances.

The slightly different weather conditions and a higher prioritisation of snow removal on cycling lanes in Copenhagen might be factors that contribute to differences in cycling between the two cities. In addition, social and cultural norms may play a role: in Copenhagen, it appears that everyone cycles, while this is not the case in Stockholm. The effect of descriptive and injunctive norms on different levels (societal, neighbourhood, family) is highly relevant to be further examined as a couple of studies indicate that is plays a role whether relevant others cycle as well and cycling is perceived as a "normal” behaviour or not (e.g., Haustein et al., 2018; Pooley et al., 2013; Pojani et al., 2017; Underwood et al., 2014). Variables representing population density and density of bicycle infrastructure in each district were included in the analysis but insignificant. This may be due to the limited variation in the data as both Copenhagen and Stockholm are central municipalities in larger urban regions, and their population densities are generally high. It may also be that the connectivity of the bicycle network is more important and that this cannot be captured by simple measures of provision at the level of districts. Indeed, research suggests that good bicycle infrastructure and networks are important for increasing cycling in cities (Buehler \& Dill, 2016; Pucher \& Buehler, 2017). Thus, the connectivity of the Copenhagen bike network, which is much better than in Stockholm, might contribute to the higher levels of cycling in Copenhagen.

With respect to public transport provision, there is a structural difference between Stockholm's metro network and the reliance upon busses in surface traffic in Copenhagen, which may again be likely to affect the speed and attractiveness of public transport over bicycles. However, the aggregate level of public transport supply appear to be comparable between the two cities.

With respect to trip distances, statistics from the City of Stockholm point to an average commute trip length of $11 \mathrm{~km}$, whereas Copenhagen residents commute $10 \mathrm{~km}$ on average. 
Thus, conditions of travel are comparable, but the slightly shorter distance for Copenhagen residents is a probable contribution to the difference between the cities reflected in the regression model.

Results in relation to socio-demographic factors partly reflect the findings of previous studies, for example that car availability decreases the level of cycling (e.g., Pucher \& Buehler, 2006). We also found an effect of employment status, namely that being a student, employed, or selfemployed is associated with higher cycling levels, which can be explained by the fact that people who cycle longer per day are more likely to be cycling commuters.

With regard to gender, we found an interaction between gender and city, namely that being female has a positive effect on cycling in Copenhagen but not in Stockholm. This is in line with previous findings according to which higher cycling frequencies for men are particularly found in countries with low overall cycling frequencies, while females tend to cycle more in high-cycling countries (Aldred et al., 2016). This is probably related to higher perceived safety in high-cycling countries, where better cycling infrastructure is provided.

Interestingly, we also found an interaction between the age of the respondents and the city, namely that older people in Stockholm cycle more (when age and age squared are controlled for), while this is not the case in Copenhagen. A reason for this might be the already mentioned congestion on cycling paths in Copenhagen, which might discourage older people in Copenhagen from cycling as compared to older people in Stockholm. Descriptive analyses show that cycling in Copenhagen is indeed more age-related than in Stockholm.

The significant effect of cycling autonomy is in line with previous research (Hunecke et al., 2010) and shows that people cycle more when they find it easy and efficient to reach their destinations by bike. However, other than expected, no significant effect of safety perceptions on the level of cycling was found. Although cyclists in Copenhagen do feel significantly safer and more secure than cyclists in Stockholm do, according to our model this does not offer an explanation for why people in Copenhagen cycle so much more than people in Stockholm. One reason for the non-significance of perceived safety and security might be that cycling safety is comparably high in both Denmark and Sweden (Pucher \& Buehler, 2006) so that perceived safety is less relevant as a factor limiting cycling as compared to countries with poor cycling infrastructure (Chataway et al., 2014). Parts of the safety and security effects might also be captured by age and gender effects. More importantly, people who do not cycle were not asked for their cycling perceptions in this study. However, among non-cyclists there 
might be a number of people who ceased cycling because of negative cycling experiences and perceptions. We thus recommend that future work also asks former cyclists about their perceptions of cycling.

In the case of the perceived prioritisation of cycling in transport planning, cyclists might have higher expectations in regions where cycling is perceived as a normal behaviour, which might explain that no significant effect was found. In the regression analysis including all respondents, assessing that cyclists are prioritised in traffic had a negative effect on the level of cycling. Probably frequent cyclists rank cyclists as being less prioritised as they are more likely to experience that users of other modes are prioritised higher, while non-cyclists might overestimate the actual prioritisation of cyclists in traffic as they perceive it from a non-cyclist perspective, where they as a driver, pedestrian or public transport user have to watch out for cyclists. Thus, the estimation of the actual prioritisation of each transport mode is most likely biased by the amount of experience people have with the respective transport mode.

Survey data can generally be biased by factors such as social desirability (e.g., Lajunen \& Summala, 2003), non-response, memory or hindsight bias (e.g., Roese \& Vohs, 2012). While our survey had a high overall response rate, the response rate varied considerably among different city districts with people in more dense and congested districts being overrepresented. We assume that participating people had a higher interest in the topic as they were more affected by traffic, which should be taken into account when interpreting the results. Slight deviations of the sample from the general city population with regard to age and gender are considered less relevant as these factors were controlled for in the regression analyses. However, they should be taken into account when interpreting the descriptive results.

\section{Conclusion}

We have compared two capital cities in Scandinavia that are generally thought to be culturally close - even in terms of urban and transport planning - but are found to be very different when it comes to cycling. Cycling frequencies are considerable higher in Copenhagen compared to Stockholm, both on weekdays and weekends and in summer and winter.

The differences in cycling frequencies are reflected in the cycling experiences and perceptions in both cities: cyclists in Copenhagen feel that they have priority in traffic, they feel safer and 
secure as cyclists, and they perceive it as more efficient to cycle to reach their destinations. Cyclists' experiences in Copenhagen are overall much more positive compared to those of cyclists in Stockholm.

However, neither the cyclists' perceptions of priority nor differences in the provision of cycling infrastructure (as operationalised in this study) can adequately explain the differences in cycling between the two cities. Socio-economic, mobility and perception variables are related to cycling levels, but the difference between the two cities seems to be beyond these well-known and anticipated effects. The difference may be related to an overall cycling culture, which we find in Copenhagen but not in Stockholm. Historically, Copenhagen and Stockholm have followed different trajectories with respect to cycling policies, which today seem to be inscribed into the citizens' priorities on which modes should receive priority in traffic and which modes they prioritise themselves. The resulting mobility cultures appear to be poorly described by individual level metrics as attempted in this study. Understanding the wider set of factors that form a cycling culture would be highly valuable to cities around the world that are aiming to stimulate cycling. Future studies should aim for additional comparisons across cultural contexts to study the basis for cycling and mobility cultures, their rigidity or changeability, as well as their role as preconditions for travel choices. 


\section{References}

Aldred, R. \& Dales, J. (2017) Diversifying and normalising cycling in London, UK: An exploratory study on the influence of infrastructure, Journal of Transport \& Health, Vol. 4, pp. 348-362

Aldred, R. \& Goodman, A. (2018) Predictors of the frequency and subjective experience of cycling near misses: Findings from the first two years of the UK Near Miss Project, Accident Analysis \& Prevention, Vol. 110, pp. 161-170

Aldred, R., Elliot, B., Woodcock, J. \& Goodman, A. (2017) Cycling provision separated from motor traffic: a systematic review exploring whether stated preferences vary by gender and age, Transport Reviews, Vol. 37(1), pp. 29-55

Aldred, R. \& Jungnickel, K. (2014) Why culture matters for transport policy: the case of cycling in the UK. Journal of Transport Geography, Vol. 34, pp. 78-87

Anable, J., \& Gatersleben, B. (2005). All work and no play? The role of instrumental and affective factors in work and leisure journeys by different travel modes. Transportation Research, Part A, Vol. 39, pp. 163-181

Banister, D. (2005) Unsustainable Transport - City transport in the new century. Routledge, London

Bere, E., van der Horst, K., Oenema, A., Prins, R., \& Brug, J. (2008) Socio-demographic factors as correlates of active commuting to school in Rotterdam, the Netherlands. Preventive Medicine, Vol. 47, pp. 412-416

Bonham, J. \& Wilson, A. (2012) Bicycling and the Life Course: The Start-Stop-Start Experiences of Women Cycling. International Journal of Sustainable Transportation, Vol. 6, pp. 195-213

Buehler, R. \& Dill, J. (2016) Bikeway Networks: A Review of Effects on Cycling. Transport Reviews, Vol. 36(1), pp. 9-27

Buehler, R., \& Pucher, J. (2012a) International Overview: Cycling Trends in Western Europe, North America, and Australia. In: Pucher, J and Buehler, R (eds.) City Cycling. The MIT Press, Cambridge, pp. 9-30 
Buehler, R., \& Pucher, J. (2012b) Big City Cycling in Europe, North America, and Australia. In: Pucher, J and Buehler, R (eds.) City Cycling. The MIT Press, Cambridge, pp. 287-318

Buehler, R. \& Pucher, J. (2012c) Cycling to work in 90 large American cities: new evidence on the role of bike paths and lanes, Transportation 39 (2), 409-432

Carstensen, T. A., \& Ebert, A.-K. (2012) Cycling cultures in Northern Europe: From "Golden Age” to "Renaissance”. In: Parkin J (ed.), Cycling and sustainability. Bingley: Emerald Group Publishing Limited, pp. 23-58

Carstensen, T.A., Olafsson, A.S., Bech, N.M., Poulsen, T.S., Zhao, C. (2015). The spatiotemporal development of Copenhagen’s bicycle infrastructure 1912-2013, Geografisk Tidsskrift-Danish Journal of Geography, Vol. 115, Iss. 2, 2015

Chataway, E. S., Kaplan, S., Nielsen, T. A. S., \& Prato, C. G. (2014) Safety perceptions and behavior related to cycling in mixed traffic: A comparison between Brisbane and Copenhagen. Transportation Research, Part F, Vol. 23, pp. 32-43

Chatman, D. G. (2014) Explaining the "immigrant effect” on auto use: The influences of neighborhoods and preferences. Transportation 41(3), pp. 441-461

Christiansen, H. (2012). Documentation of the Danish National Travel Survey. Kongens Lyngby, Denmark: Technical University of Denmark, Transport.

City of Copenhagen (1996). København - Cyklernes by, Cykelregnskab 1995, Københavns Kommune, Magistratens 4. afdeling og Magistratens 2. afdeling.

City of Copenhagen (2011) Good, Better, Best - the City of Copenhagen’s bicycle strategy 2011-2025. The City of Copenhagen, Technical and Environmental Administration, Traffic Department

City of Copenhagen (2014) http://www.kk.dk/files/2014-hoejesteuddanpdf, accessed 201602-02

City of Copenhagen (2017) http://www.kk.dk/files/2016befolkningenefterbydeleogarealpdf, accessed 2017-04-28

City of Stockholm (2013) http://www.stockholm.se/OmStockholm/Fakta-och-kartor/, accessed 2016-02-02 
City of Stockholm (2017) http://statistik.stockholm.se/oversiktlig-statistik, accessed 2017-0428

City of Stockholm (2018) http://statistik.stockholm.se/detaljerad-statistik, accessed, 2018-0813

Cresswell, T. (2010) Towards a politics of mobility. Environment and Planning D: Society and Space, Vol. 28, pp. 17-31

de Bruijn, G. J., Kremers, S. P., Schaalma, H., van Mechelen, W., \& Brug, J. (2005)

Determinants of adolescent bicycle use for transportation and snacking behavior. Preventive Medicine, Vol. 40, pp. 658-667

de Bruijn, G. J., Kremers, S. P., Singh, A., Van den Putte, B., \& Van Mechelen, W. (2009). Adult active transportation: adding habit strength to the theory of planned behavior. American Journal of Preventive Medicine, Vol. 36(3), pp. 189-194

Danmarks Statistik (2018). Folketal 1. januar efter kommune, tid, køn og alder, www.statistikbanken.dk, accessed 2018-08-26

DMI - The Danish Meteorological Institute (2017) http://www.dmi.dk/vejr/arkiver/normalerog-ekstremer/klimanormaler-dk/, accessed 2017-04-28

Ellaway A., Macintyre S., Hiscock, R., \& Kearns, A. (2003). In the driving seat: psychosocial benefits from private motor vehicle transport compared to public transport. Transportation Research, Part F, Vol 6, pp. 217-231

European Union (2011) Mapping guide for a European Urban Atlas, GMES: Global Monitoring for Environment and Security. European Environment Agency, Copenhagen European Commission (2017). Copernicus Land Monitoring Service - Reference Data EUDEM, European Environment Agency: Copenhagen

Fishman, E. (2016) Cycling as transport. Transport Reviews, Vol. 36(1), pp. 1-8Frank LD, Sallis JF, Saelens BE, Leary L, Cain K, Conway TL, Hess PM (2010) The development of a walkability index: application to the neighbourhood quality of life study, British Journal of Sports Medicine, Vol. 44, pp. 924-933 
Freudendal-Pedersen, M. (2015a) Whose Commons are Mobilities Spaces? - The Case of Copenhagen's Cyclists. ACME: An International E-Journal for Critical Geographies, Vol. 14(2), pp. 598-621

Freudendal-Pedersen, M. (2015b) Cyclists as Part of the City’s Organism: Structural Stories on Cycling in Copenhagen. City \& Society, Vol. 27(1), pp. 30-50

Garrard, J. (2003) Promoting cycling among women. Health promotion journal of Australia, Vol. 14(3), pp. 213-215

Garrard, J., Rissel, C., \& Bauman, A. (2012) Health Benefits of Cycling. In: Pucher, J. and Buehler, R. (eds.) City Cycling. The MIT Press, Cambridge, pp. 31-56

Garson, G. D. (2014) Ordinal Regression. Asheboro, NC: Statistical Associates Publishers. Gatersleben, B., \& Appleton, K. M. (2007) Contemplating cycling to work: attitudes and perceptions in different stages of change. Transportation Research Part A, Vol. 41(4), pp. 302-312

Götschi, T., Garrad, J. \& Giles-Corti, B. (2016) Cycling as a Part of Daily Life: A Review of Health Perspectives. Transport Reviews, Vol. 36(1), pp. 45-71

Götz, K., Deffner, J., \& Klinger, T. (2016). Mobilitätsstile und MobilitätskulturenErklärungspotentiale, Rezeption und Kritik. In: O. Schöller, W. Canzler, A. Knie (Eds.): Handbuch Verkehrspolitik. Wiesbaden: VS Verlag für Sozialwissenschaften.

Handy, S., Van Wee, B., \& Kroesen, M. (2014). Promoting cycling for transport: research needs and challenges. Transport reviews, Vol. 34(1), pp. 4-24.

Haustein, S. (2012) Mobility behavior of the elderly: an attitude-based segmentation approach for a heterogeneous target group. Transportation, Vol. 39(6), pp. 1079-1103

Haustein, S., Kroesen, M., \& Mulalic, I. (2018). Modelling the effect of foreign origin on mode choice in two different cycling cultures. Presentation at the 7th Symposium of the European Association for Research in Transportation conference (hEART), Athens, Greece, 5-7 September 2018.

Haustein, S., \& Nielsen, T. A. S. (2016). European mobility cultures: A survey-based cluster analysis across 28 European countries. Journal of Transport Geography, Vol. 54, pp. 173-180 
Heesch, K. C., Sahlqvist, S., \& Garrard, J. (2012) Gender differences in recreational and transport cycling: a cross-sectional mixed-methods comparison of cycling patterns, motivators, and constraints. International Journal of Behavioral Nutrition and Physical Activity, Vol. 2, 9(1), 106

Heinen, E., Maat, K., \& van Wee, B. (2011) The role of attitudes toward characteristics of bicycle commuting on the choice to cycle to work over various distances. Transportation Research, Part D, Vol. 16, pp. 102-109

Heinen, E., van Wee, B. \& Maat, K. (2010) Commuting by bicycle: An overview of the literature. Transport Reviews, Vol. 30(1), pp. 59-96

Hunecke, M., Haustein, S., Böhler, S., \& Grischkat, S. (2010) An attitude based target group approach to reduce the ecological impact of daily mobility behavior. Environment and Behavior, Vol. 42, pp. 3-43

Hunecke, M., Haustein, S., Grischkat, S., \& Böhler, S. (2007) Psychological, sociodemographic, and infrastructural factors as determinants of ecological impact caused by mobility behavior. Journal of Environmental Psychology, Vol. 27(4), pp. 277-292

Klinger, T., Kenworthy, J. R., \& Lanzendorf, M. (2013) Dimensions of urban mobility cultures-a comparison of German cities. Journal of Transport Geography, Vol. 31, pp. 18-29 Klinger, T., \& Lanzendorf, M. (2015) Moving between mobility cultures: what affects the travel behavior of new residents? Transportation Research Board, Vol. 1807, pp. 163-173 Københavns Kommune (2014), Befolkning efter bydele og areal, City of Copenhagen, www.kk.dk/statistik, accessed 2015-12-18

Koglin, T. (2013) Vélomobility - A critical analysis of planning and space. Doctoral Dissertation, Lund University, Department of Technology and society, Transport and Roads, 2013, Bulletin 284

Koglin, T. (2015a) Organisation does matter - planning for cycling in Stockholm and Copenhagen. Transport Policy, Vol. 39, pp. 55-62

Koglin, T. (2015b) Vélomobility and the politics of transport planning. GeoJournal, Vol. 80, pp. 569-586 
Koglin, T. (2017) Urban mobilities and materialities - A critical reflection of a "sustainable” development project, Applied Mobilities, Vol. 2(1), pp. 32-49

Koglin, T. (2018) Urban Velomobility and the Spatial Problems of Cycling. In FreudendalPedersen, Hartmann-Petersen and Perez Fjalland (eds.) Experiencing Networked Urban Mobilities. Routledge, New York

Koglin, T. \& Rye, T. (2014) The marginalisation of bicycling in Modernist urban transport planning. Journal of Transport and Health, Vol. 1(4), pp. 214-222

Lajunen, T. \& Summala, H. (2003). Can we trust self-reports of driving? Impression management on driver behaviour questionnaire responses. Transportation Research Part F: Traffic Psychology and Behaviour, 6, pp. 97-107.

Lanzendorf, M. \& Busch-Geertsema, A. (2014) The cycling boom in large German cities Empirical evidence for successful cycling campaigns. Transport Policy, Vol. 36, pp. 26-33

Latham, A. \& Wood, P.R.H. (2015) Inhabiting infrastructure: exploring the interactional spaces of urban cycling. Environment and Planning A, Vol. 47, pp. 300-319

Lindelöw, D. (2009) Strategier för ett ökat gående och cyklande - en litteraturstudie om olika faktorers betydelse. Bulletin 249 - Lund University, Faculty of Engineering, Department of Technology and Society

Madsen, T., Schipperijn, J. J., Troelsen, J., Christiansen, L. B. S., Duncan, S., \& Nielsen, T. A. S. (2013). Associations between neighbourhood walkability and cycling in Denmark. Cycling Research International, 3, 154-170.

Nielsen, T. A. S., Olafsson, A. S., Carstensen, T. A., \& Skov-Petersen, H. (2013a)

Environmental correlates of cycling: Evaluating urban form and location effects based on Danish micro-data. Transportation Research. Part D, Vol. 22, pp. 40-44

Nielsen, T. A. S., Skov-Petersen, H., \& Carstensen, A. T. (2013b) Urban planning practices for bikeable cities - the case of Copenhagen. Urban Research \& Practice, Vol. 6(1), pp. 110 115

Nuhn, H. and Hesse, M. (2006) Verkehrsgeographie - Reihe: Grundriss Allgemeine Geographie. Verlag Ferdinand Schöningh, Paderborn OpenStreetMap-multiple contributors (2015). https://www.openstreetmap.org/, accessed 
Pelzer, P. (2010) Bicycling as a way of life: A comparative case study of bicycle culture in Portland, OR and Amsterdam. Paper Presented to the 7th Cycling and Society Symposium, Oxford, UK, Retrieved 20.10.2015 from http://www.tsu.ox.ac.uk/events/100906/css-pelzerpaper.pdf

Pojani, D., Bakija, D., Shkreli, E., Corcoran, J., \& Mateo-Babiano, I. (2017) Do Northwestern and Southeastern Europe share a common "Cycling Mindset”? Comparative analysis of beliefs toward cycling in the Netherlands and the Balkans. EJTIR, Vol. 17(1), pp. 25-45

Pooley, C.G., Horton, D., Scheldeman, G., Mullen, C., Jones, T., Tight, M., Jopson, A. \& Chisholm, A. (2013) Policies for promoting walking and cycling in England: A view from the street. Transport Policy, 27, pp. 66-72

Pucher, J., \& Buehler, R. (2006) Why Canadians cycle more than Americans: a comparative analysis of bicycling trends and policies. Transport Policy, 13(3), pp. 265-279

Pucher, J., \& Buehler, R. (2008) Making cycling irresistible: Lessons from The Netherlands, Denmark and Germany. Transport Reviews, Vol. 28, pp. 495-528

Pucher, J. \& Buehler, R. (2017) Cycling towards a more sustainable transport future. Transport Reviews, Vol. 36(6), pp. 689-694

Roese, N.J. \& Vohs, K. D. (2012) Hindsight bias. Perspectives on Psychological Science 7(5), pp. 411-426.

Sottile, E., Sanjust di Teulada, B., Meloni, I., \& Cherchi, E. (2018). Estimation and validation of hybrid choice models to identify the role of perception in the choice to cycle. International Journal of Sustainable Transportation, published online. DOI:

10.1080/15568318.2018.1490465

Smart, M. (2010) US immigrants and bicycling: Two-wheeled in Autopia. Transport Policy 17(3), pp. 153-159

SMHI - The Swedish Meteorological and Hydrological Institute (2017) http://data.smhi.se/met/climate/time_series/day/temperature/SMHI_day_temperature_clim_97 20.txt, accessed 2017-04-28 
Statistiska Centralbyrån (2018). Folkmängd efter region, ålder, kön och år, www.statistikdatabasen.scb.se, accessed 2018-08-26

Steg, L. (2005) Car use: Lust and must. Instrumental, symbolic and affective motives for car use. Transportation Research, Part A, Vol. 39, pp. 147-162

Stockholms Stad (2014) Statistical Year-book of Stockholm 2015, Vol. 108, City of Stockholm, Stockholm

Tal, G., \& Handy, S. (2010) Travel behavior of immigrants: An analysis of the 2001 National Household Transportation Survey. Transport Policy, 17(2), pp. 85-93

van Goeverden, K., Nielsen, T. A. S., Harder, H., \& van Nes, R. (2015) Interventions in Bicycle Infrastructure, Lessons from Dutch and Danish Cases. Transportation Research Procedia, Vol. 10, pp. 403-412

Van Wee, B. (2007) Environmental Effects of Urban Traffic. In Gärling and Steg (eds.) Threats from Car Traffic to the Quality of Urban Life - Problems, Causes and Solutions. Elsevier, Amsterdam 